\title{
Quantitative Risk Analysis of Offshore Fire and Explosion Based on the Analysis of Human and Organizational Factors
}

\author{
Yan Fu Wang, ${ }^{1}$ Yu Lian Li, ${ }^{1}$ Biao Zhang, ${ }^{1}$ Pei Na Yan, ${ }^{1}$ and Li Zhang ${ }^{2}$ \\ ${ }^{1}$ Department of Safety Science and Engineering, China University of Petroleum, Qingdao 266580, China \\ ${ }^{2}$ Jiangsu Academy of Safety Science and Technology, Nanjing 210042, China \\ Correspondence should be addressed to Yan Fu Wang; 66923203@qq.com
}

Received 12 May 2015; Accepted 30 June 2015

Academic Editor: Xiaobo Qu

Copyright (c) 2015 Yan Fu Wang et al. This is an open access article distributed under the Creative Commons Attribution License, which permits unrestricted use, distribution, and reproduction in any medium, provided the original work is properly cited.

\begin{abstract}
A dynamic risk analysis model of offshore fire and explosion is proposed in this paper. It considers the effect of human and organizational factors in a more explicit way than current traditional risk analysis methods. This paper begins with exploring the recent advances on offshore fire and explosion risk analysis theories, followed by briefly introducing the research techniques employed in the proposed hybrid causal logic model which consists of event tree, fault tree, Bayesian network, and system dynamics. Thereafter, it proposes a quantitative risk analysis framework. At last, the applicability of this model to the offshore platform is also discussed. It aims to provide guideline for risk analysis of offshore fire and explosion.
\end{abstract}

\section{Introduction}

Over the past two decades, a number of serious accidents including the Piper Alpha accident have attracted public concerns over offshore safety and reliability. Offshore platform is in a harsh environment due to highly concentrated equipment, a large amount of explosive substances, oil/gas pipelines, and flange leak sources. Hydrocarbon fires and explosions are extremely hazardous on offshore platforms. The fire and explosion will not only result in significant casualties and economic losses, but also cause serious pollution and damage to surrounding environment and coastal marine ecosystems [1]. The high cost of offshore platforms, fire/explosion severity, and complexity of marine environment determine the necessity and difficulty of fire/explosion risk analysis [2]. How to propose efficient safety measures to prevent the escalation of such accidents requires comprehensive knowledge of accident-related phenomena, as well as the tools of adequate risk analysis [3].

Historical statistics show that the majority of offshore fire and explosion accidents are caused by human and organizational error (HOE) [4]. As a result, Norway and UK offshore legislation and guidelines require that $\mathrm{HOE}$ analysis should be included in quantitative risk analysis. However, the mainstream offshore fire/explosion risk analysis methods focus more on probability of equipment and structures failure. Recently, some attempt to build human reliability analysis models used in quantitative risk analysis chose to leverage expert information due to lack of HOE data. There have been repeated calls to expand the technical basis of human reliability analysis by systematically integrating information from different domains. Thus refining and improving analytic methods of human reliability analysis to more accurately simulate and quantify the impact of HOE have become a matter of urgency.

This paper is organized as follows. Section 2 analyzes the recent advances on offshore fire and explosion risk assessment. Section 3 briefly introduces event tree, fault tree, Bayesian network (BN), and system dynamics. Then, in Section 4, a dynamic quantitative risk analysis framework is proposed and its applicability for the offshore platform is also discussed, followed by conclusions in Section 5 .

\section{Recent Advances of Offshore Fire and Explosion Risk Analysis}

Quantitative risk analysis involves four main steps: hazard identification, consequence assessment, probability calculation, and finally risk quantification [5-8]. Three kinds of 
researches on offshore fire/explosion risk analysis are carried out worldwide: the first one is using statistical methods to predict fire/explosion risk based on historical data [9]; the second one is carrying out risk analysis using commercial software [10]; the third one is integrating new theory with traditional risk assessment methods [11].

In this section, a literature review is carried out to identify existing methods for risk assessment of offshore fire and explosion.

2.1. Consequence Analysis of Offshore Fire and Explosion. Some offshore fire/explosion risk assessment studies focus on consequences and impacts analysis: Krueger and Smith demonstrate how a scenario-based approach of fire risk assessment can be effectively applied to calculate potential impacts of credible fire scenarios on the platform process equipment, structural members, and safety systems [12]. Pula et al. considered fire consequence modeling as a suite of submodels such as individual fire models, radiation model, overpressure model, smoke and toxicity models, and human impact models. This comprehensive suite of models was then revised and its performance is compared with the ones used in a commercial software package for offshore risk assessment $[13,14]$. Suardin et al. adopted a grid-based approach for fire and explosion assessment to enable better consequence/impact modeling and enhanced on-site ignition model. This approach features built-in calculations for jet and pool fire size estimation for gas/liquid releases and the ability to perform quantitative risk analysis to specify the personnel and equipment risk [15]. The Joint Industry Project carries out a series of experimental tests to evaluate the load characteristics of steel and concrete tubular members under jet fire to investigate the jet fire load characteristics [16] and to examine the effect of wind on the thermal diffusion characteristics of floating production storage and offloading [17]. Moreover, a modeling technique for computational fluid dynamics simulations of hydrocarbon explosions and fire is developed [18]. These insights developed will be very useful for the fire engineering of floating production storage and offloading topsides.

2.2. Frequency Analysis of Offshore Fire and Explosion. There are also few offshore fire/explosion risk assessment studies focused on frequency and probability analysis: Ronza et al. [19] analyzed the correlations of ignition probability and the mass flow rate by analyzing tens of thousands of records of hydrocarbon spills by HMIRS (a database about hazardous materials incident reporting system). Moosemiller [20] develops the algorithms based on a variety of design, operating, and environmental conditions to calculate probabilities of immediate ignition and delayed ignition resulting in explosion. On the other hand, Vinnem proposes failure models for hydrocarbon leaks during maintenance work in process plants on offshore petroleum installations based on seventy hydrocarbon leaks accidents [21]. Because major accidents are always of low frequency, data collected from them are not sufficient. As a result, it is very difficult to use conventional statistical methods to analyze them. In order to improve the situation, a methodology has been proposed based on hierarchical Bayesian analysis and accident precursor data to do risk analysis of major accidents [22].

Based on the aforementioned works on leak frequency and ignition modeling, many researchers have proposed new methodologies for frequency analysis of offshore fire and explosion. The Joint Industry Project introduces a number of procedures [9] and reviews the state-of-the-art technologies [23] for quantitative assessment and management of fire and gas explosion risks in offshore installations focusing on defining the frequency of fires and explosions in offshore installations. Aside from the application of the fault tree, event tree, and BN [24-27], a methodology [28] based on Bow-tie and real time predictive models is proposed to conduct dynamic risk assessment of the drilling operations. The application of the Bow-tie model is used to analyze the potential accident scenarios, their causes, and the associated consequences. Real time predictive models for the failure probabilities of key barriers are developed to conduct dynamic risk assessment of the drilling operations. Vinnem et al. [29] proposed the Risk_OMT model combining the traditional quantitative risk analysis models and HOE analysis through Risk Influence Factor model, for quantitative risk analysis of platform specific hydrocarbon release frequency. The risk of fire and explosion in floating production storage and offloading is quantitatively assessed by Dan et al., in which the consequence is simulated by PHAST and the frequency is analyzed based on the analysis of historical data using event tree model [30].

The current generation of quantitative risk analysis does not include the quantitative impacts of HOE on the safety performance of equipment and personnel. There are a number of technical challenges in developing an offshore fire and explosion risk analysis model based on the effect analysis of HOE.

\subsection{Effect Analysis of Human and Organizational Error to Off-} shore Fire and Explosion Risk. With the extension of human reliability research field from human-machine systems to human inherent factors (psychology, emotion, and behavior), increasing attention has been paid to the relationship between HOE and offshore fire/explosion risk. The relevant references are shown as follows: an extensive survey $[31,32]$ is followed to identify the relationship between HOE and hydrocarbon leaks on Norwegian oil and gas producing platforms. The results from regression analysis on survey data show that the psychosocial risk indicator significantly impacts frequency of hydrocarbon leaks.

Although it is generally acknowledged that HOE has a significant impact on the fire and explosion risk, it is difficult to quantify how the HOE affects the fire and explosion risk due to scarcity of $\mathrm{HOE}$ data and uncertainty of $\mathrm{HOE}$. In order to deal with the problem, Musharraf et al. [33] addressed the issue of handling uncertainty associated with expert judgments with evidence theory and described the dependency among the human factors and associated actions using BN. They also present a virtual experimental technique 


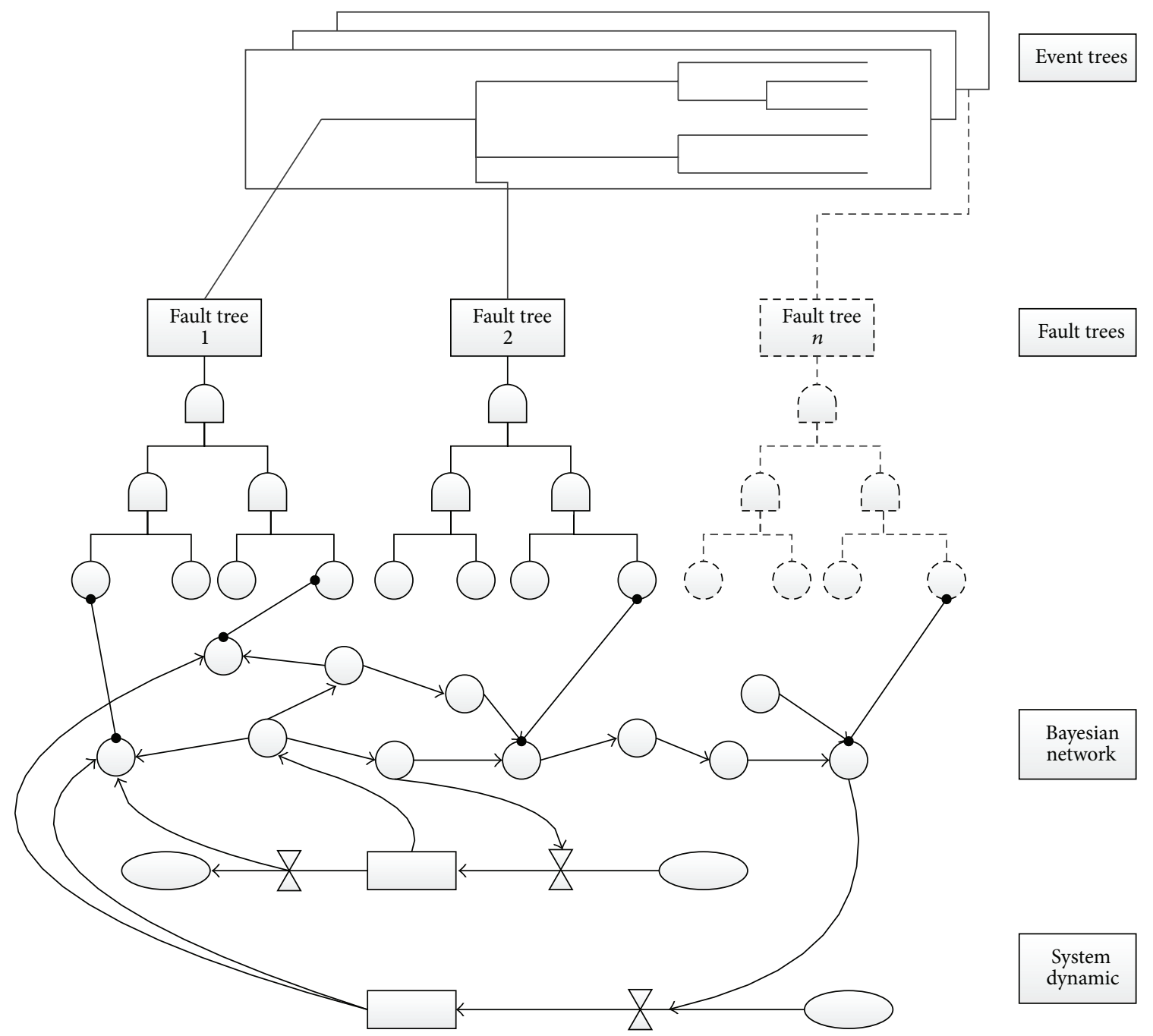

FIGURE 1: The proposed hybrid framework.

for data collection for BN to human reliability analysis. Groth et al. [34] proposed the use of $\mathrm{BN}$ to formally incorporate simulator data into estimation of human error probabilities.

\section{Quantitative Risk Analysis of Offshore Fire and Explosion Based on Human and Organizational Errors}

In this section, a dynamic quantitative risk analysis model of offshore fire and explosion is built by incorporating the effect of HOE.

3.1. Incorporating Human and Organizational Factors into Quantitative Risk Analysis. A method of applying $\mathrm{BN}$ in risk analyses has been suggested in the hybrid causal logic framework and fully developed by letting $\mathrm{BN}$ be logically and probabilistically integrated into fault tree. Thereafter, some parts of the risk analysis can be addressed in fault tree, while others are addressed in BN. Event tree/fault tree are often considered as the best option for technical aspects, while HOEs in many cases fit better into a BN. By taking the advantages of the three techniques, the result of combining event tree/fault tree and $\mathrm{BN}$ is normally a more detailed risk model with higher resolution.

The above hybrid causal logic model can express the static relationships between logical variables. However, it cannot deal with dynamic characteristics of process variables and human behavior. In order to quantify the dynamic influence of HOEs on the total risk, system dynamics is combined with the above hybrid causal logic model. The new framework is illustrated in Figure 1, which shows the link between system dynamics, BN, event tree, and fault tree. The first interface in this hybrid framework is the one between $\mathrm{BN}$ and event tree/fault tree. System dynamics model describes dynamic deterministic relations and provides a dynamic integration among the other two models. In the proposed framework, different models will have both inputs and outputs to the system dynamics model to allow the entire hybrid framework to capture feedback and delays. 


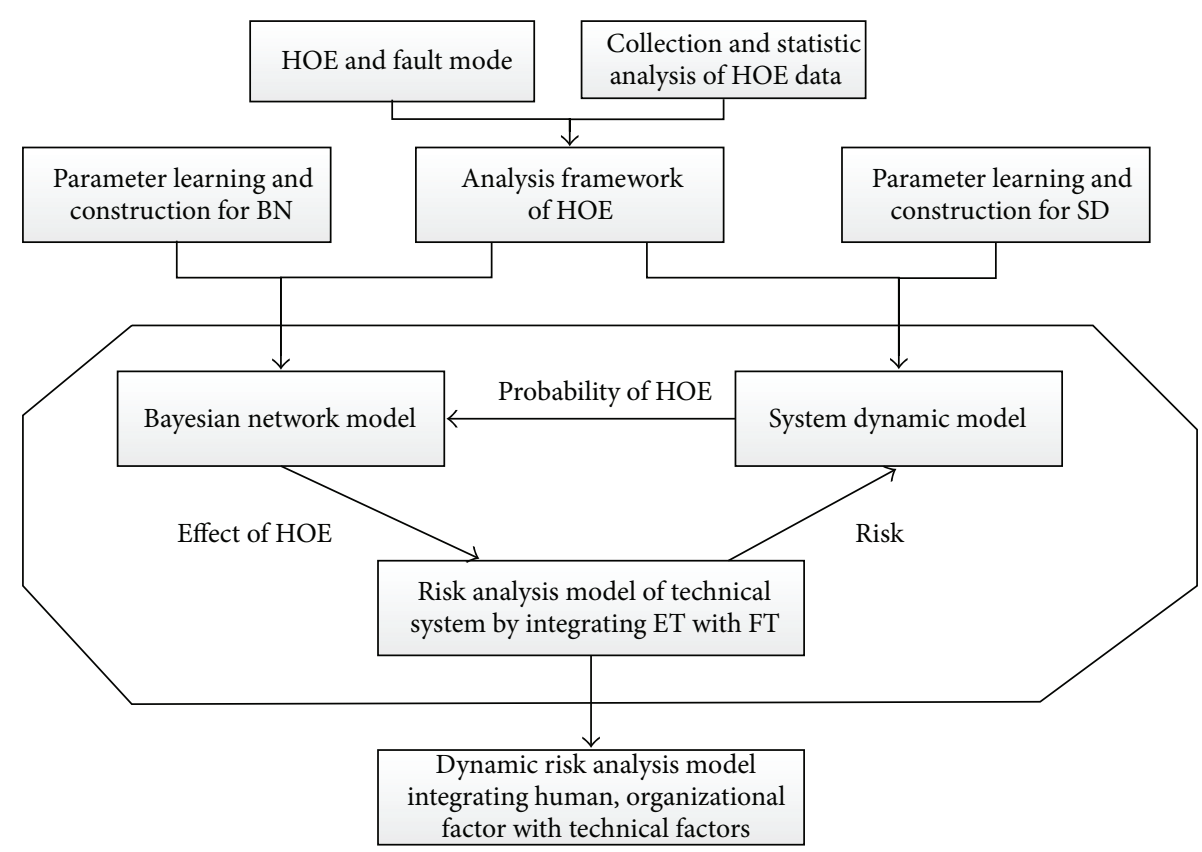

FIGURE 2: Dynamic risk analysis model integrating human and organizational factors with technical factor.

Based on Figure 1, a dynamic risk analysis model is proposed by integrating human and organizational factors with technical factor as shown in Figure 2.

Firstly, historical HOE data are collected and statistically analyzed to build a HOE framework using the proposed hybrid causal logic. Parameter learning and construction of $\mathrm{BN}$ and system dynamics model are researched separately to build a more refined HOE model. The interface of system dynamics with BN, event tree, and fault tree can be captured by importing and exporting the data from system dynamics model. The target node calculated from $\mathrm{BN}$ is imported to system dynamics and processed inside system dynamics, and the estimated values from system dynamics can be exported to $\mathrm{BN}$. The interaction effects of various factors could be researched in this cyclic process. At last, a dynamic quantitative risk analysis model is built by integrating human and organizational factors with technical factors.

3.2. Quantitative Risk Analysis Model of Offshore Fire and Explosion Based on the Effect Analysis of HOEs. As shown in Section 3.1, the dynamic effects of human, organizational, and technical factors to system risk are quantitatively simulated by integrating system dynamics and $\mathrm{BN}$ with event tree and fault tree. Based on this, a quantitative risk analysis model for offshore fire and explosion is discussed from both consequence and probability perspective in this section and is illustrated in Figure 3.

3.2.1. Consequence Analysis of Offshore Fire and Explosion. Firstly, a set of hydrocarbon release scenarios, including the position, the size of latent leak source, and ignition source, are defined by hazard identification study using FMEA method. The purpose is to identify and describe the scenarios that may lead to fire/explosion of offshore platform. The most credible fire/explosion scenarios are fixed via Latin Hypercube sampling methods.

Every scenario is simulated using FLACS to characterize the fire/explosion load profiles according to temperature and heat amount. The structure consequences of fire/explosion are simulated via nonlinear structural analysis. The personnel consequences of fire/explosion are analyzed considering the exposed individuals and the fire/explosion load of every accident scenario. For example, potential loss of life (PLL) can be calculated by the following equation:

$$
\mathrm{PLL}=\sum_{n}^{N} \sum_{j}^{J} F_{n j} \cdot C_{n j}
$$

where $F_{n j}=$ annual frequency of scenario $n$ with personnel consequence $j, C_{n j}=$ the expected number of fatalities for scenario $n$ with personnel consequence $j, N=$ the total number of scenarios, and $J=$ the total number of the consequence types, including immediate fatalities, escape fatalities, and rescue fatalities.

3.2.2. Probability Analysis of Offshore Fire and Explosion. Historical data about leak, fire, and explosion of offshore platform are collected and statistically analyzed. Based on this, the fire and explosion frequency model is constructed by integrating event tree/fault tree and $\mathrm{BN}$ with system dynamics: the failures of safety barriers preventing offshore fire and explosion are analyzed using event tree/fault tree to develop a risk analysis model for technical systems; the dynamic effects of HOE on leak frequency and ignition probability are quantitatively simulated by integrating system dynamics with $\mathrm{BN}$. The system dynamics module depicts 


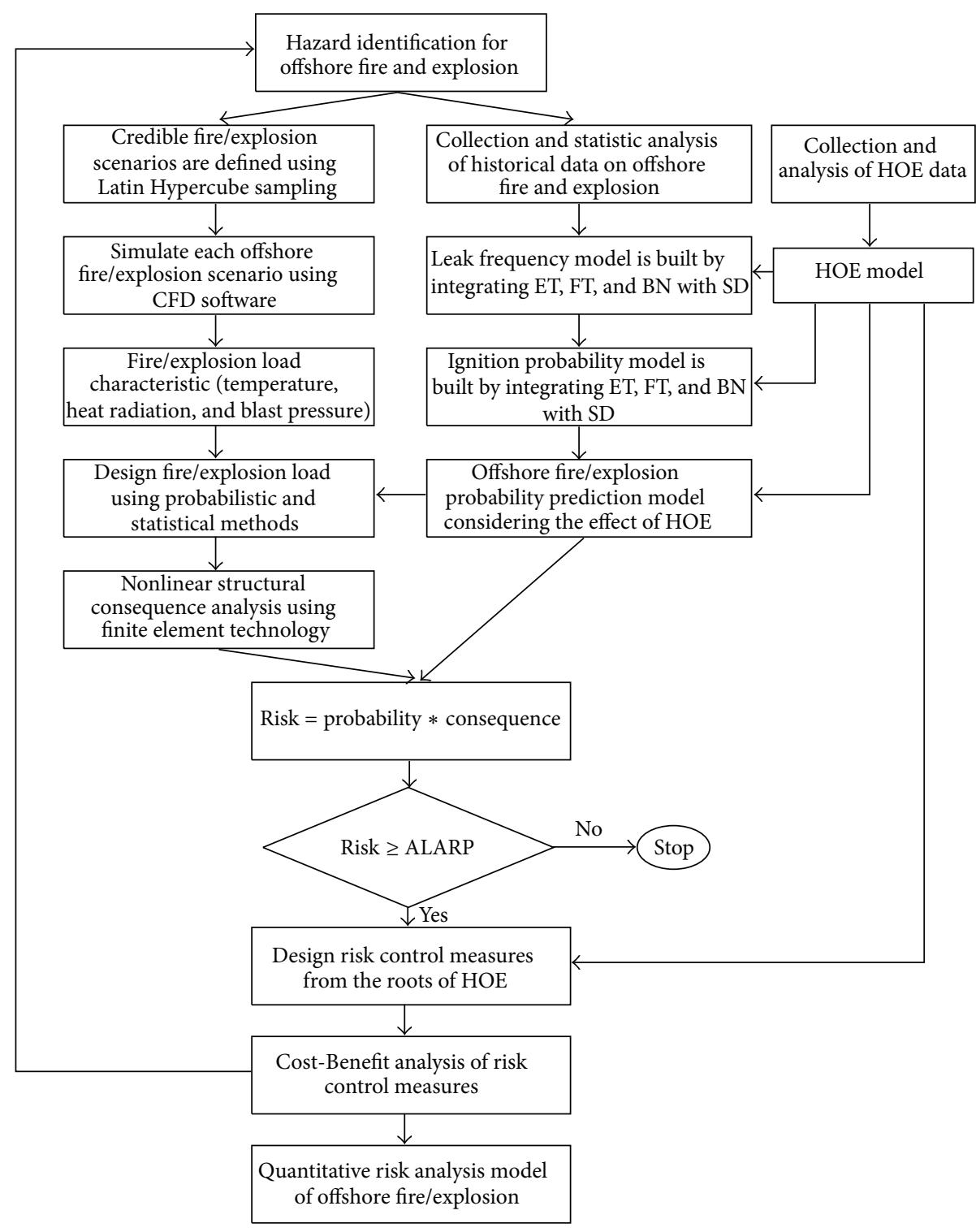

FIGURE 3: Quantitative risk analysis model of offshore fire and explosion.

dynamic deterministic relations in the proposed hybrid causal logic model and provides a dynamic integration among event tree/fault tree and BN model.

Review and analysis of historical documents are performed to get the offshore industry average probabilities/ frequencies of human, organizational, and technical factor, which are assigned to the initiating events and the basic events in the hybrid causal logic model and carry out a quantitative analysis of the offshore fire and explosion frequency by using these data. The results of this calculation may to some degree reflect offshore platform specific conditions since specific data should be applied when possible. Offshore platform data may be found in, for example, incident databases, log data, and maintenance databases. In practice, extensive use of industry average data is necessary to be able to carry out the quantitative analysis. Several databases are available presenting offshore industry average data like OREDA for equipment reliability data and THERP and CORE-DATA for HOE data. In some cases, neither offshore platform specific data nor generic data may be found, and it may be necessary to use expert judgment to assign probabilities.

3.2.3. Risk Analysis of Offshore Fire and Explosion. As shown in Figure 3, the fire and explosion risk of offshore platform can be calculated as the product of frequency and consequences. If the calculated risk level is greater than the acceptable risk level, then the risk control options should be adopted from the root of human and organizational factors. The adopted risk control options should be evaluated using CostBenefit analysis method to get the most beneficial measures to reduce the fire/explosion risk of offshore platform.

"As low as reasonably practicable" principle is defined in terms of exceeding damage probability for main safety functions or probability of accident escalation. The "as low 


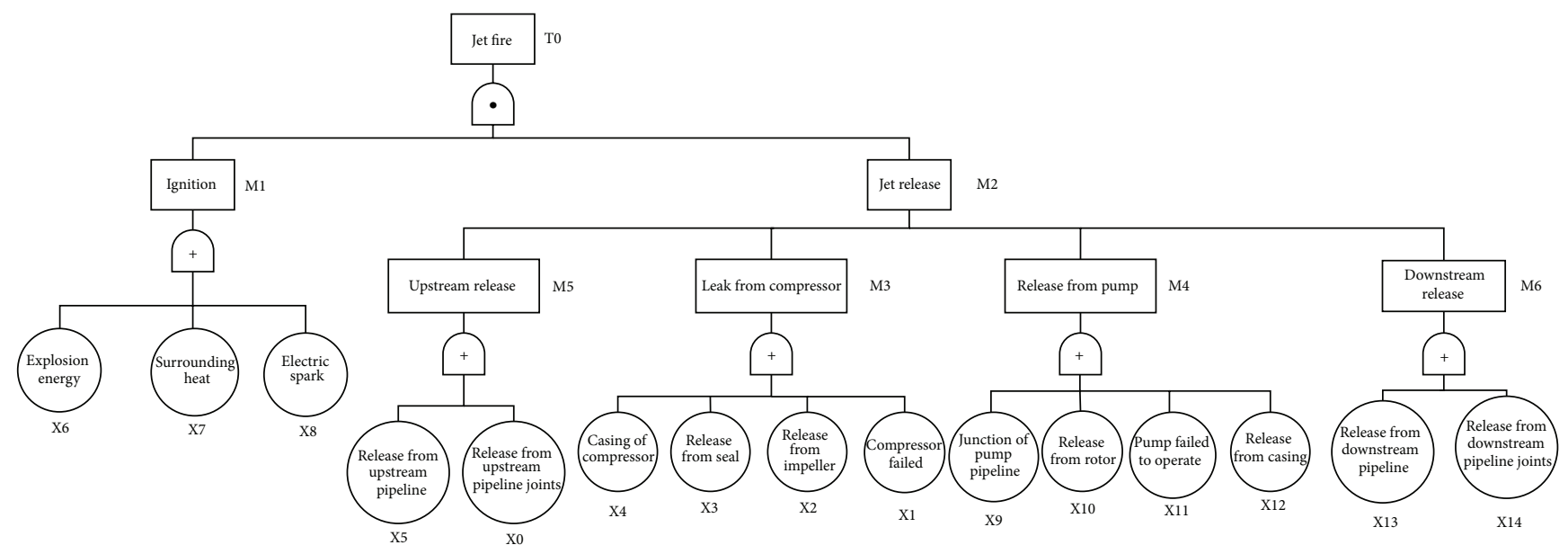

FIGURE 4: Fault tree of jet fire.

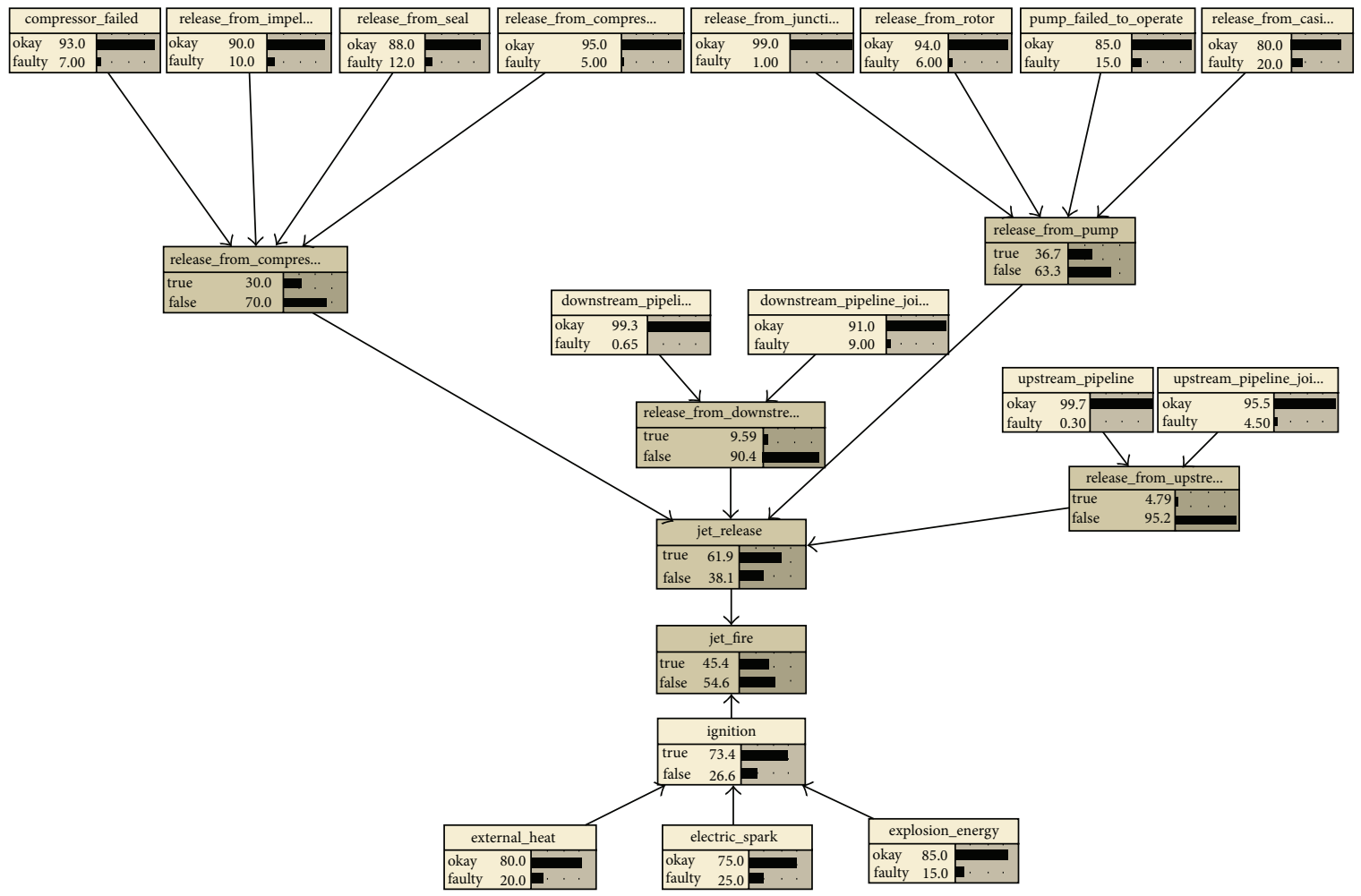

FIGURE 5: Bayesian network of jet fire.

as reasonably practicable" principle in conjunction with the results of quantitative risk analysis can be used to manage and reduce the risks to the lowest level that is reasonably practicable.

\section{Case Study for Fire Probability Analysis on Offshore Platform}

In this section, the proposed model in Section 3.1 is demonstrated on a simple case study of jet fire on offshore platform. The detailed scenarios are analyzed using fault tree as shown in Figure 4. The probability data of basic events were collected from Offshore Reliability Data Handbook [35], World-Wide Offshore Accident Databases, and reports by HSE [2].

The basic events, their important degree of probability, and failure probability are shown in Table 1.

The probability of jet fire is 0.505938 according to the calculation results of fault tree. From the calculation for importance degree of probability, it can be seen that the effects of X6, X7, and X8 on the probability of jet fire are larger than other basic events. The fault tree shown in Figure 4 can be converted into $\mathrm{BN}$, which is drawn in Figure 5. 
TABLE 1: The failure probability and basic events of fault tree.

\begin{tabular}{|c|c|c|c|}
\hline & Basic event & Failure probability & Importance degree of probability \\
\hline $\mathrm{X} 0$ & Release from joints of upstream pipeline & 0.045 & 0.00865 \\
\hline $\mathrm{X} 1$ & Compressor completely failed causing release & 0.07 & 0.00865 \\
\hline $\mathrm{X} 2$ & Release from impeller & 0.1 & 0.00865 \\
\hline $\mathrm{X} 3$ & Release from seal & 0.12 & 0.00865 \\
\hline $\mathrm{X} 4$ & Release from casing of compressor & 0.05 & 0.00865 \\
\hline X5 & Release from upstream pipeline & 0.048 & 0.00865 \\
\hline $\mathrm{X} 6$ & Ignition due to explosion energy & 0.15 & 0.01231 \\
\hline $\mathrm{X} 7$ & Ignition due to external heat from surrounding & 0.2 & 0.0124 \\
\hline $\mathrm{X} 8$ & Ignition due to electric spark & 0.25 & 0.01314 \\
\hline X9 & Release from junction of pump and pipeline & 0.01 & 0.00865 \\
\hline $\mathrm{X} 10$ & Release from rotor & 0.06 & 0.00865 \\
\hline X11 & Pump failed to operate causing release & 0.15 & 0.00865 \\
\hline $\mathrm{X} 12$ & Release from casing & 0.2 & 0.00865 \\
\hline $\mathrm{X} 13$ & Release from downstream pipeline & 0.0065 & 0.00865 \\
\hline $\mathrm{X} 14$ & Release from joints of downstream pipeline & 0.09 & 0.00865 \\
\hline
\end{tabular}

TABLE 2: Conditional probability and mutual information of basic event.

\begin{tabular}{lccc}
\hline Basic event & $\begin{array}{c}\text { Prior probability } \\
(\%)\end{array}$ & $\begin{array}{c}\text { Posterior } \\
\text { probability (\%) }\end{array}$ & 7.4 \\
information
\end{tabular}

From BN inference shown in Figure 5, it can be seen that the occurrence probability of jet fire is computed as 0.0917 per year. The prior probability, posterior probability, and mutual information (entropy reduction) of each basic event are compared, which is shown in Table 2.

From Table 2, it can be concluded that "external heat," "explosion energy," and "electric spark" have the larger contribution to the occurrence of jet fire. The BN shown in Figure 5 is extended by incorporating the effect of human and organizational factors as shown in Figure 6.

The prior probability, posterior probability, and mutual information (entropy reduction) of each human and organization factor are compared as shown in Table 3.
From Table 3, it can be seen that human factor "not_ comply_with_instruction" and organizational factor "inefficient_emergency_plan" have the largest contribution to the occurrence of the eventual fire accident. This analysis shows that particular attention should be paid to "comply with instruction" and "efficient emergency plan."

Dynamic quantitative risk analysis is carried out by integrating human and organizational factors with technical factors (see Figure 7).

The simulation results of Figure 7 are shown in Figure 8.

Figure 8 displays the probability trend that could be traced in jet fire, ignition, and jet release in a period of 10 years. The advantage of the dynamic model over those of 


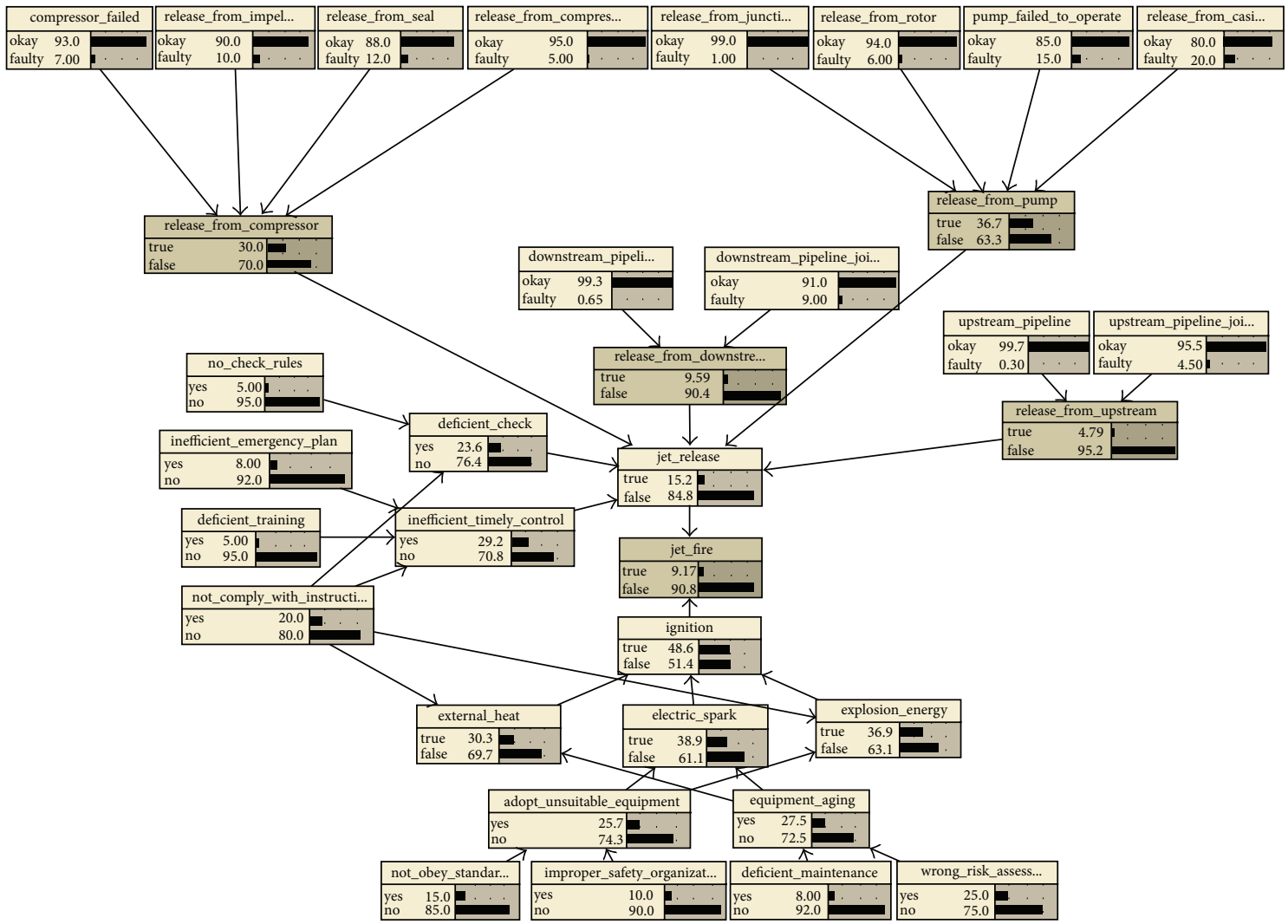

FIGURE 6: Extended Bayesian network considering human and organizational factors.

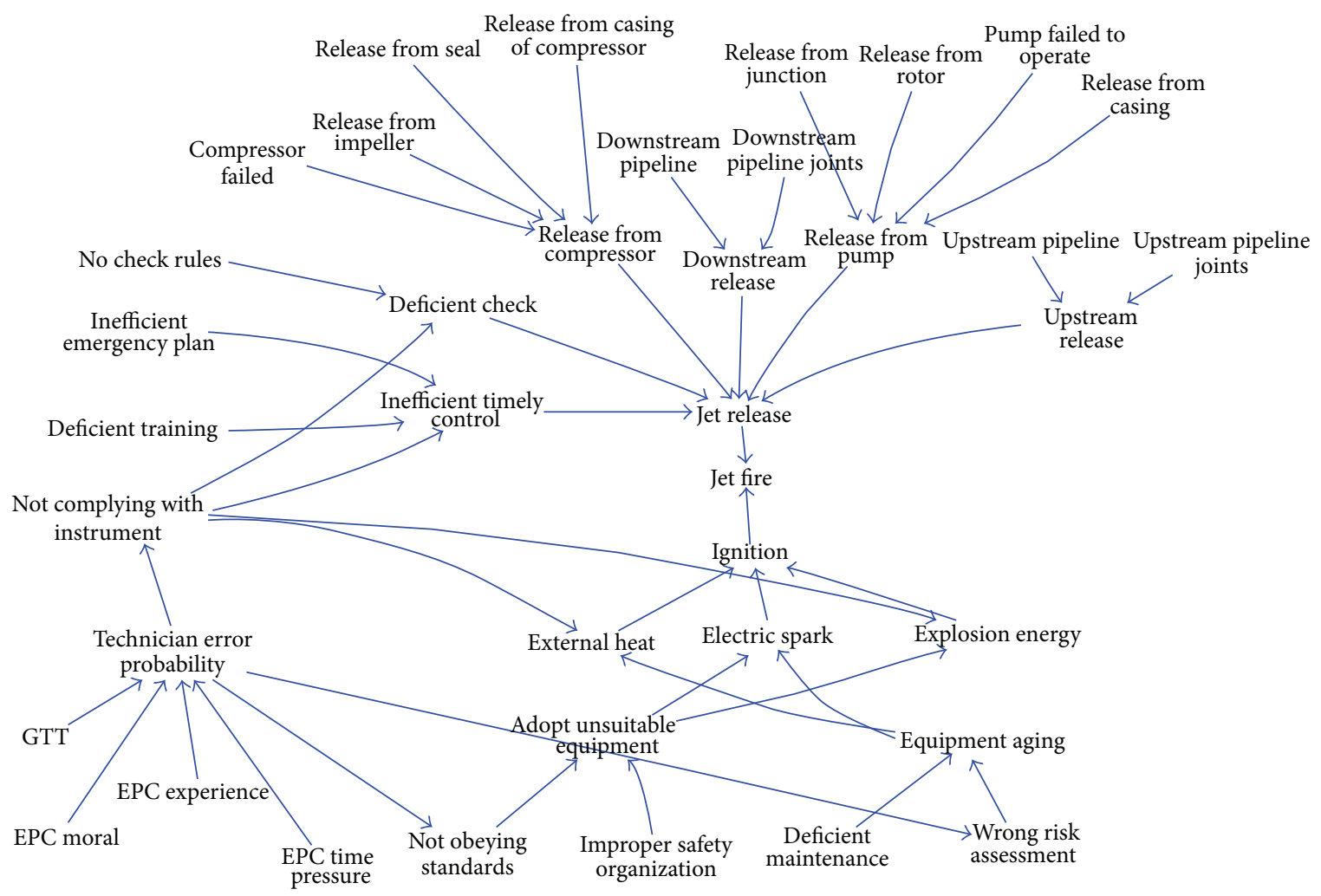

FIGURE 7: Dynamic risk analysis of jet fire using system dynamics. 
TABLE 3: Conditional probability and mutual information of human and organization factor.

\begin{tabular}{lccc}
\hline Basic event & Prior probability (\%) & Posterior probability (\%) & Mutual information \\
\hline no_check_rules & 5 & 5.6 & 0.0000537 \\
not_comply_with_instruction & 20 & 75.2 & 0.107 \\
inefficient_emergency_plan & 8 & 13.4 & 0.002483 \\
deficient_training & 5 & 8.85 & 0.001914 \\
improper_safety_organization & 10 & 11.3 & 0.0001325 \\
not_obey_standards & 15 & 17.3 & 0.0002871 \\
deficient_maintenance & 8 & 8.85 & 0.0000702 \\
wrong_risk_assessment & 25 & 26.7 & 0.0001054 \\
\hline
\end{tabular}
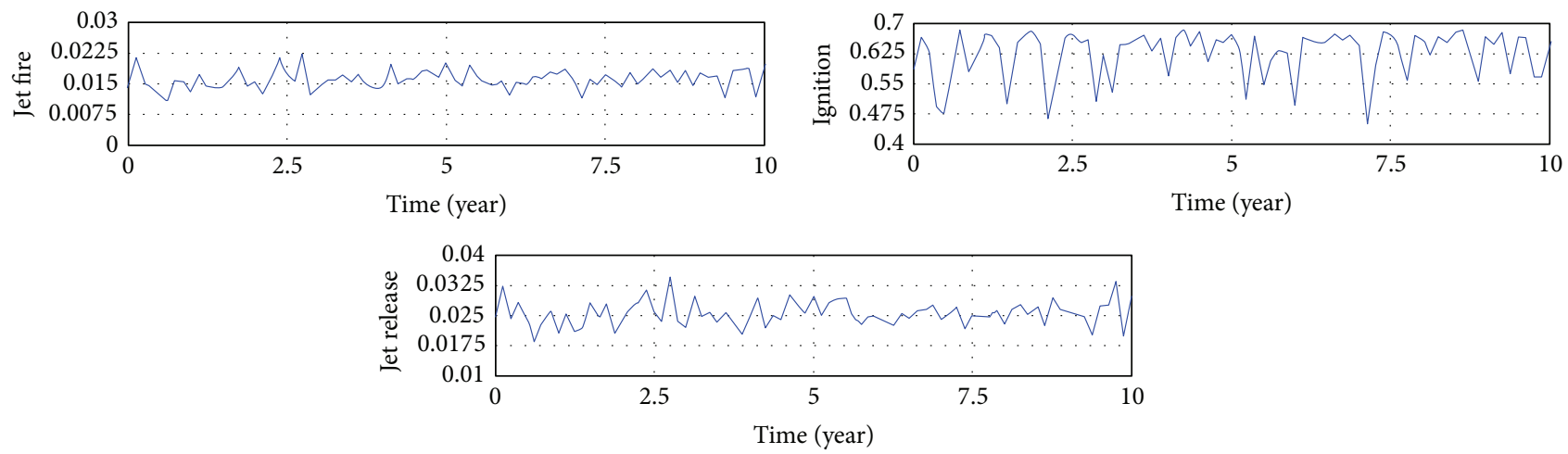

FIGURE 8: Jet fire probability varies with time during a period of ten years.

static models is that it can show the dynamic probability variation with time.

\section{Conclusion}

The exploration of accidents in light of human error linked to underlying factors related to the human and organization work has been established as a major priority. In order to improve traditional risk assessment methods without considering HOE, new risk assessment methods need to be researched further based on analyzing HOE. The purpose of this paper is to simulate the dynamic effect of HOE on offshore fire/explosion risk, and its contributions can be summarized as follows:

(1) A hybrid framework, including an integration of system dynamics, BN, event tree, and fault tree, is built to analyze the dynamic offshore fire/explosion risk based on the effect analysis of HOE. The proposed model is demonstrated on a simple case study of jet fire on offshore platform.

(2) The hybrid framework integrates deterministic and probabilistic modeling techniques, which can be used to analyze the dynamic effects of HOEs on the risk of complex social-technical system.

(3) The quantitative risk analysis framework for offshore fire and explosion is discussed from both consequence and probability perspective.
(4) The effective prevention measures to reduce the risk of offshore fire/explosion can be designed from the root of HOE. This will provide guideline for risk management of offshore platform.

\section{Conflict of Interests}

The authors declare that there is no conflict of interests regarding the publication of this paper.

\section{Acknowledgments}

This paper is supported by the National Natural Science Foundation of China (Grant no. 51409260), the Fundamental Research Funds for the Central Universities (Grant no. 14CX05035A), and Shandong Province Natural Science Fund Project (Grant no. ZR2012EEM023).

\section{References}

[1] HSE, "Offshore accident," Incident Statistics Reports OTO96.954, HSE, London, UK, 1996.

[2] HSE, Accident Statistics for Floating Offshore Units on the UK Continental Shelf (1980-2003), HSE, 2005.

[3] J. K. Paik and J. Czujko, "Explosion and fire engineering and gas explosion of FPSOs (phase I): hydrocarbon releases on FPSOs - review of HSE's accident database," Final Report No. EFEF JIP-02, Research Institute of Ship and Offshore Structural 
Design Innovation, Pusan National University, Busan, Korea, 2009.

[4] R. G. Bea, "The role of human error in design. Construction and reliability of the marine structure," U. S. A. Ship Structure Committee Report SSC2378, 1994.

[5] X. Qu, Y. Yang, Z. Liu, S. Jin, and J. Weng, "Potential crash risks of expressway on-ramps and off-ramps: a case study in Beijing, China," Safety Science, vol. 70, pp. 58-62, 2014.

[6] Q. Meng, J. Weng, and X. Qu, "A probabilistic quantitative risk assessment model for the long-term work zone crashes," Accident Analysis and Prevention, vol. 42, no. 6, pp. 1866-1877, 2010.

[7] Q. Meng, X. Qu, K. T. Yong, and Y. H. Wong, "QRA model based risk impact analysis of traffic flow in urban road tunnels," Risk Analysis, vol. 31, no. 12, pp. 1872-1882, 2011.

[8] Q. Meng, X. Qu, X. Wang, V. Yuanita, and S. C. Wong, "Quantitative risk assessment modelling for non-homogeneous urban road tunnels," Risk Analysis, vol. 31, no. 3, pp. 382-403, 2011.

[9] J. K. Paik, J. Czujko, B. J. Kim et al., "Quantitative assessment of hydrocarbon explosion and fire risks in offshore installations," Marine Structures, vol. 24, no. 2, pp. 73-96, 2011.

[10] L.-B. Li, Z.-L. Wang, Q. Yin, and Y.-J. Sun, "Study on influencing factors of risk of offshore platforms under fire and gas explosion disaster," The Ocean Engineering, vol. 29, no. 2, pp. 92-98, 2011.

[11] W. Røed, A. Mosleh, J. E. Vinnem, and T. Aven, "On the use of the hybrid causal logic method in offshore risk analysis," Reliability Engineering and System Safety, vol. 94, no. 2, pp. 445455, 2009.

[12] J. Krueger and D. Smith, "A practical approach to fire hazard analysis for offshore structures," Journal of Hazardous Materials, vol. 104, no. 1-3, pp. 107-122, 2003.

[13] R. Pula, F. I. Khan, B. Veitch, and P. R. Amyotte, "Revised fire consequence models for offshore quantitative risk assessment," Journal of Loss Prevention in the Process Industries, vol. 18, no. 4-6, pp. 443-454, 2005.

[14] R. Pula, F. I. Khan, B. Veitch, and P. R. Amyotte, "A grid based approach for fire and explosion consequence analysis," Process Safety and Environmental Protection, vol. 84, no. 2, pp. 79-91, 2006.

[15] J. A. Suardin, A. Jeff McPhate Jr., A. Sipkema, M. Childs, and M. S. Mannan, "Fire and explosion assessment on oil and gas floating production storage offloading (FPSO): an effective screening and comparison tool," Process Safety and Environmental Protection, vol. 87, no. 3, pp. 147-160, 2009.

[16] B. J. Kim, J. K. Seo, J. H. Park et al., "Load characteristics of steel and concrete tubular members under jet fire: an experimental and numerical study," Ocean Engineering, vol. 37, no. 13, pp. 1159-1168, 2010.

[17] J. Y. Yoon, S. H. Kim, G. C. Yu et al., "Effects of wind on the heat flow of fpso topsides subject to fire: an experimental and numerical study," in Proceedings of the ASME 29th International Conference on Ocean, Offshore and Arctic Engineering, pp. 949-958, June 2010.

[18] J. K. Paik, B. J. Kim, J. S. Jeong et al., "CFD simulations of gas explosion and fire actions," Ships and Offshore Structures, vol. 5, no. 1, pp. 3-12, 2010.

[19] A. Ronza, J. A. Vílchez, and J. Casal, "Using transportation accident databases to investigate ignition and explosion probabilities of flammable spills," Journal of Hazardous Materials, vol. 146, no. 1-2, pp. 106-123, 2007.

[20] M. Moosemiller, "Development of algorithms for predicting ignition probabilities and explosion frequencies," Journal of Loss
Prevention in the Process Industries, vol. 24, no. 3, pp. 259-265, 2011.

[21] J. E. Vinnem, "On the development of failure models for hydrocarbon leaks during maintenance work in process plants on offshore petroleum installations," Reliability Engineering and System Safety, vol. 113, no. 1, pp. 112-121, 2013.

[22] N. Khakzad, F. Khan, and N. Paltrinieri, "On the application of near accident data to risk analysis of major accidents," Reliability Engineering and System Safety, vol. 126, pp. 116-125, 2014.

[23] J. K. Paik and J. Czujko, "Assessment of hydrocarbon explosion and fire risks in offshore installations: recent advances and future trends," IES Journal-Part A: Civil and Structural Engineering, vol. 4, no. 3, pp. 167-179, 2011.

[24] Y.-F. Wang, M. Xie, M. S. Habibullah, and K.-M. Ng, "Quantitative risk assessment through hybrid causal logic approach," Proceedings of the Institution of Mechanical Engineers, Part O: Journal of Risk and Reliability, vol. 225, no. 3, pp. 323-332, 2011.

[25] Y. F. Wang, S. Faghih Roohi, X. M. Hu, and M. Xie, "Investigations of human and organizational factors in hazardous vapor accidents," Journal of Hazardous Materials, vol. 191, no. 1-3, pp. 69-82, 2011.

[26] Y. F. Wang, M. Xie, K.-S. Chin, and X. J. Fu, “Accident analysis model based on Bayesian Network and Evidential Reasoning approach," Journal of Loss Prevention in the Process Industries, vol. 26, no. 1, pp. 10-21, 2013.

[27] Y. F. Wang, M. Xie, K. M. Ng, and M. S. Habibullah, "Probability analysis of offshore fire by incorporating human and organizational factor," Ocean Engineering, vol. 38, no. 17-18, pp. 20422055, 2011.

[28] M. Abimbola, F. Khan, and N. Khakzad, "Dynamic safety risk analysis of offshore drilling," Journal of Loss Prevention in the Process Industries, vol. 30, no. 1, pp. 74-85, 2014.

[29] J. E. Vinnem, R. Bye, B. A. Gran et al., "Risk modelling of maintenance work on major process equipment on offshore petroleum installations," Journal of Loss Prevention in the Process Industries, vol. 25, no. 2, pp. 274-292, 2012.

[30] S. Dan, C. J. Lee, J. Park, D. Shin, and E. S. Yoon, "Quantitative risk analysis of fire and explosion on the top-side LNGliquefaction process of LNG-FPSO," Process Safety and Environmental Protection, vol. 92, pp. 430-441, 2014.

[31] J. E. Vinnem, J. A. Hestad, J. T. Kvaløy, and J. E. Skogdalen, "Analysis of root causes of major hazard precursors (hydrocarbon leaks) in the Norwegian offshore petroleum industry," Reliability Engineering and System Safety, vol. 95, no. 11, pp. 1142-1153, 2010.

[32] L. I. V. Bergh, A. J. Ringstad, S. Leka, and G. I. J. M. Zwetsloot, "Psychosocial risks and hydrocarbon leaks: an exploration of their relationship in the Norwegian oil and gas industry," Journal of Cleaner Production, vol. 84, no. 1, pp. 824-830, 2014.

[33] M. Musharraf, D. Bradbury-Squires, F. Khan, B. Veitch, S. Mackinnon, and S. Imtiaz, "A virtual experimental technique for data collection for a Bayesian network approach to human reliability analysis," Reliability Engineering and System Safety, vol. 132, pp. 1-8, 2014.

[34] K. M. Groth, C. L. Smith, and L. P. Swiler, "A Bayesian method for using simulator data to enhance human error probabilities assigned by existing HRA methods," Reliability Engineering and System Safety, vol. 128, pp. 32-40, 2014.

[35] Det Norske Veritas, OREDA-Offshore Reliability Data Handbook, Det Norske Veritas, Høvik, Norway, 2009. 


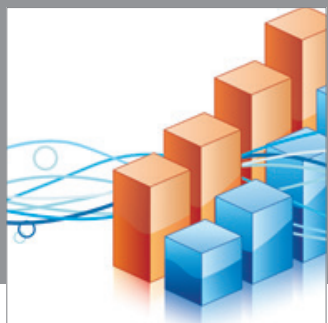

Advances in

Operations Research

mansans

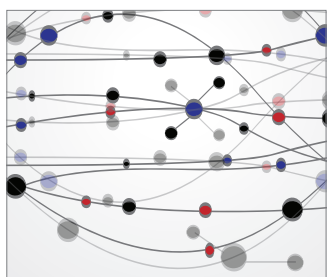

The Scientific World Journal
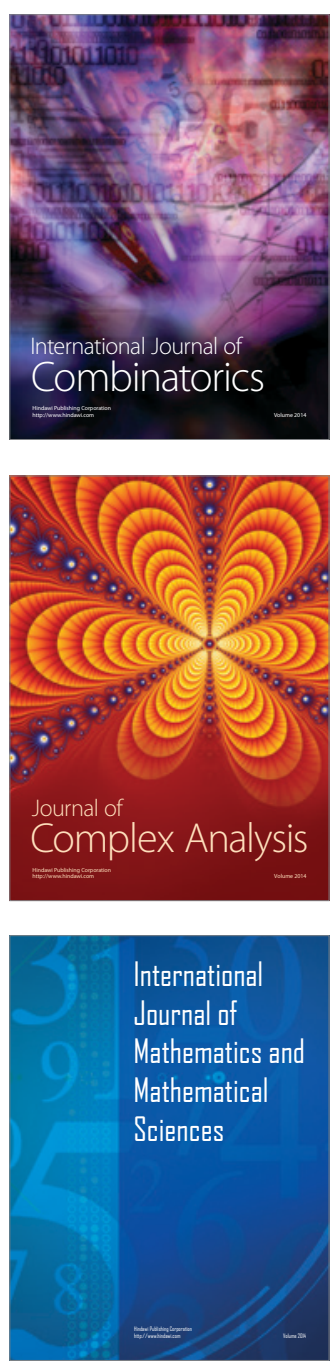
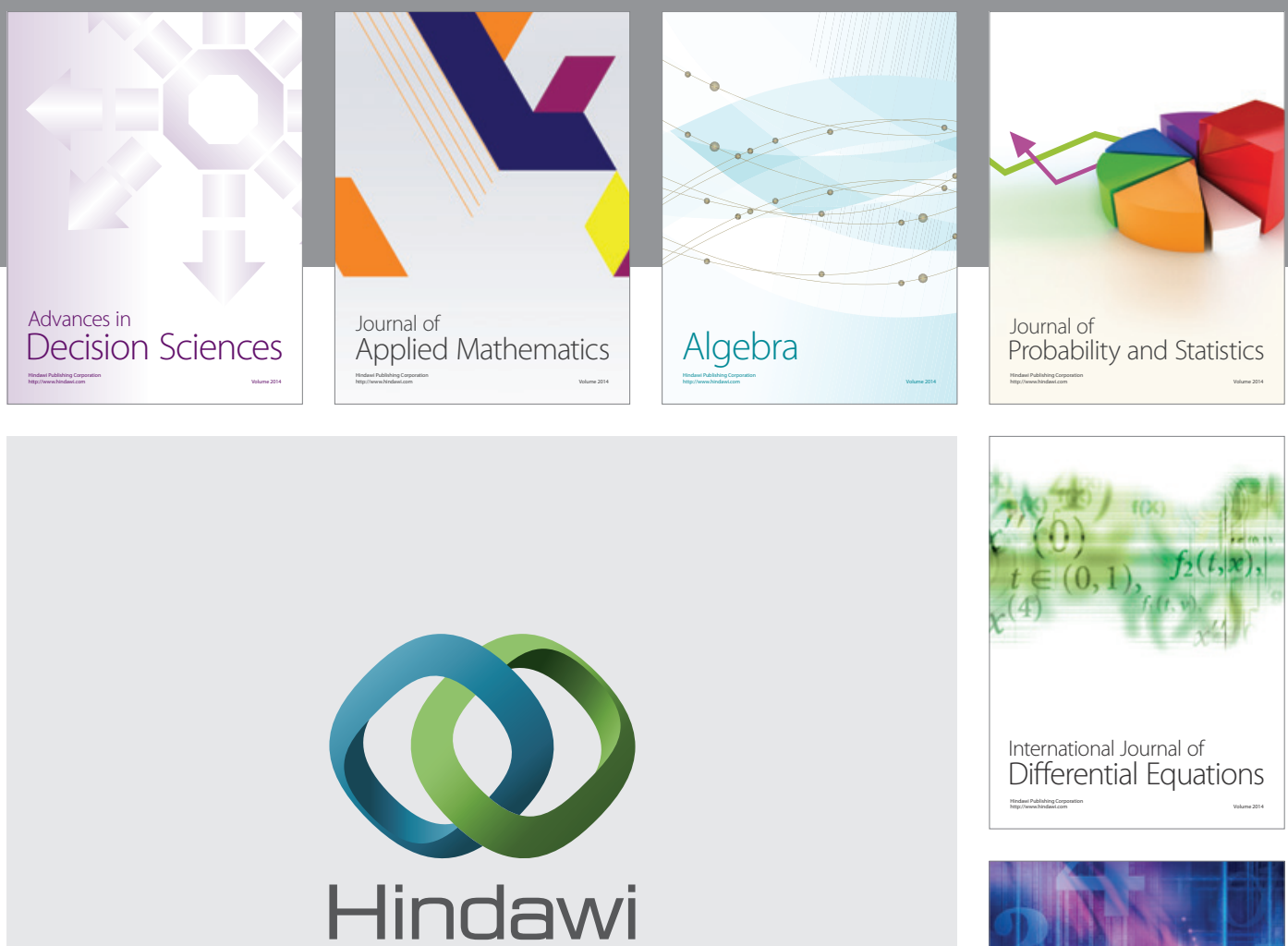

Submit your manuscripts at http://www.hindawi.com
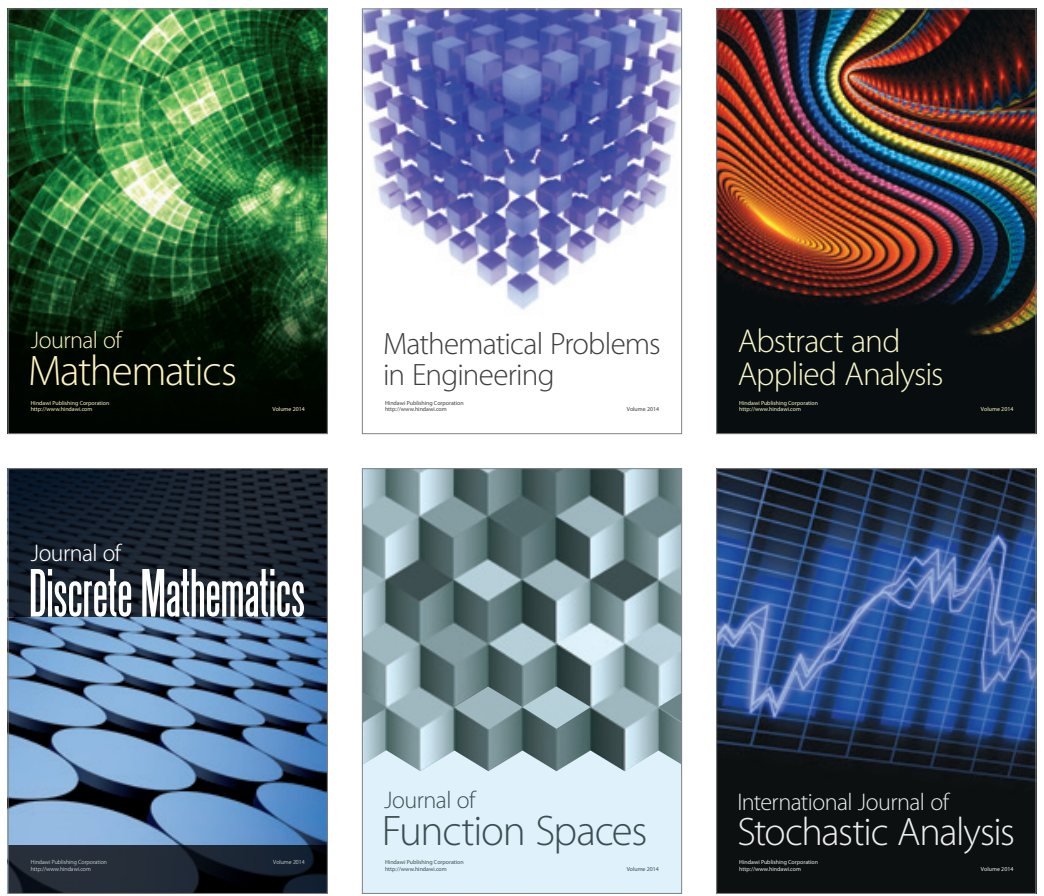

Journal of

Function Spaces

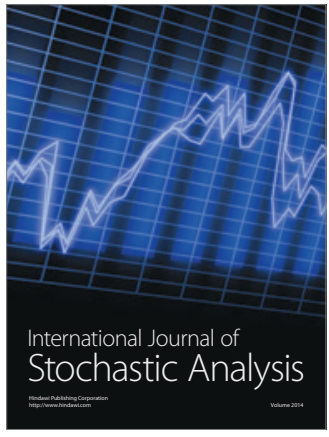

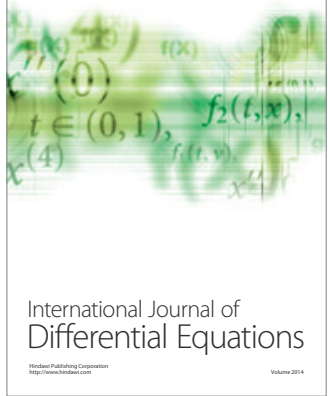
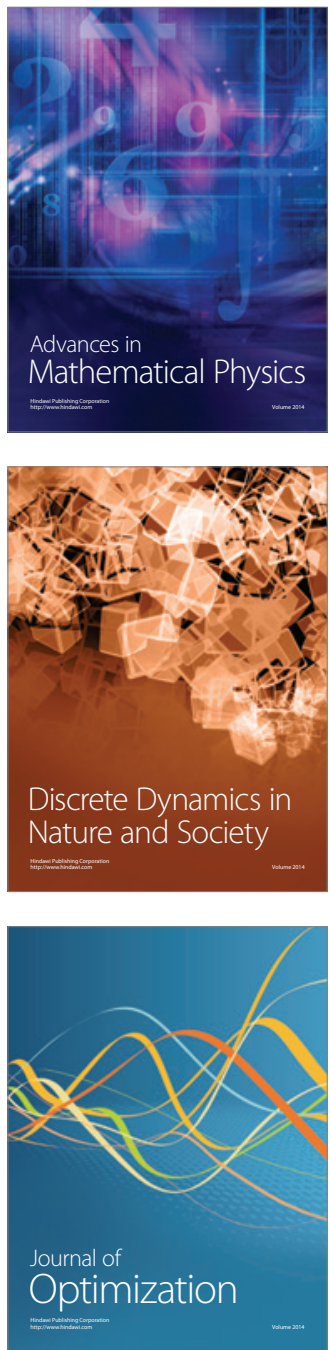